\title{
SYRIA IN ITS ARAB SPRING SWINGING BETWEEN SHAKY STABILITY AND BLOODY CHAOS
}

\author{
Hanan Al- Radhi ${ }^{1 *}$, Prof. Dr. Ambigapathy Pandian², Prof. Dr. Tengku Sepora Tengku Mehdi ${ }^{3}$ \\ ${ }^{* 1}$ A Lecturer of English Language-University of Baghdad Ph.D Candidate -USM/Malaysia Email: \\ halradhi2012@gmail.com \\ ${ }^{2}$ Email: ambiga@usm.my School of Languages, Literacies and Translation \\ ${ }^{3}$ Email: Sepora@usm.my School of Languages, Literacies and Translation
}

*Corresponding Author: -

Email: halradhi2012@gmail.com

\begin{abstract}
: -
This study aimed to explore Arab spring consequences that prevailed in Syria after 2010-2011 as reflected by CNN in its online news articles released in its website 2013. The main concern of the study is to unveil CNN's hidden ideologies towards Arab spring upheaval in Syria investigating its discoursal "Self" and "Other" representations. To achieve this goal, the researcher utilized the following theories: 1) van Dijk's theory of Semantic Macrostructure (1980); to examine macro and micro structures of CNN's online news article, 2) van Dijk's theory of Ideological Square (1998c); to examine CNN's ideologies embedded within its online news article and 3) Wodak's Discourse-Historical Approach; to endorse linguistic and ideological analysis of CNN's online news article. Fairclough's three-dimensional Approach was utilized to organize the process of analysis of the study text. Within the linguistic analysis, macro and micro structures of CNN's online news articles were analyzed. At the macro level, the semantic macrostructure was outlined to determine its global meaning. At the micro level, the syntactic, lexical and rhetorical structures were examined to determine their local meaning. Within the ideological analysis, the CNN's online news article was analyzed to determine its ideological positive "Self" (in-group) and negative "Other" (out-group) presentations. The findings revealed that CNN's ideological orientations towards Syria were varied. Thus, it presented the Syrian internal conflict as the positive "Self" identities while the Syrian regime as the negative "Other" identities.
\end{abstract}

Keywords: - Critical Discourse Analysis (CDA); Media Discourse; Ideology; Macro and Micro Structures; "Self" and "Other" presentations; Syria; CNN.

\section{(우 $($ (1)}




\section{INTRODUCTION}

A direct reproduction of communicative events cannot be achieved in media news representation due to the fact that it involves a process of selection and formulation of such events via language (Fairclough, 1995b). As such, language can be regarded as the main tool to convince people to accept certain media representations of news events which must be organized logically and naturally for the sake of spreading the views of dominant people and then accepting them as common -sense knowledge providers (Fairclough, 1995b). Accordingly, all news representations are reported from a particular angle because all media institutions and organizations are politically, socially and financially situated (Fowler, 1991).

Critical discourse analysis (henceforth CDA) can be applied in the analysis of online news as it helps create and increase awareness understanding of the linguistic strategies used to build "Self" and "Other" ideological representations. In this study, it is regarded as a necessary approach to uncover the implicit ideologies hidden in the CNN's online discourse concerning the Arab spring consequences in Syria. As such, the researcher of the present study intends to concentrate on the ideological usage of language to construct the "Self" and "Other" polarities embedded within the CNN's online news article.

\section{Objective}

The present study aims to identify the semantic macro and micro structures of CNN's Arab spring online article and its ideological representations of "Self" and "Other" towards the Arab spring consequences in Syria. As such, it will be an attempt to answer the following question:

-What are the semantic macro and micro structures of CNN's Syrian Arab spring online article and its ideological representations of "Self" and "Other"?

\section{Theoretical Framework}

The proposed model of CDA adopted in this study is based on:

\section{Van Dijk's Theory of Semantic Macrostructures}

Van Dijk (1980) provided a method to analyze the structural organization of news text. According to him, news reports have a hierarchal schema named a superstructure that has certain categories, with the most important details come before the less important ones. The global superstructure represents the overall structural organization of a news text which covers the main event, commentary, background and evaluation categories. Each category is associated with a topic or a macroproposition. The news text covers many macropropositions which can be reduced to the main one that summarizes the news text as a whole. The textual-structural categories can be exploited to steer the reader's comprehension and interpretation. This theory will be utilized to analyze the headlines and the body of CNN's news reports, under study.

\section{Van Dijk's Theory of Ideological Square}

Defining ideology as a basic shared, socio-cognitive system of a group, culture or society, van Dijk (1998a) suggested the ideological square to be applied to analyze any type of a news text, showing our positive Self-presentation and their negative Other-presentation. Words may be exploited to refer to ideological conventions, creating a suitable model in the readers' minds (Ali, 2011). This notion facilitates the comprehension of these news texts, influencing the reader's interpretation of them. The present paper utilizes the ideological square to interpret CNN 's positive "Self" (in-group) and negative "Other" (out-group) as far as the Arab spring consequences events in Syria is concerned.

\section{Wodak's Historical-Discoursal Approach}

Wodak's approach $(2001,2009)$ provides background information with which the discursive event is embedded. Hence, it is useful to expose the implicit meaning of a news text to be explicit by relating it to the relevant historical -sociopolitical situations in which it happened. Such information will be of a great help to guide the reader to comprehend the news text. This method can be used with the analysis of semantic macrostructure or with the ideological analysis. To comprehend the Syrian communicative event, it is useful to apply this approach to achieve an objective analysis. CNN 's ideological view can be understood by integrating the historical, socio and political context with the whole process of analysis.

The two theories and approach support each other, working together to create and clarify the overall meaning of the news texts, in question.

\section{Fairclough's Three-Dimensional Approach (1995a)}

Fairclough's Three-dimension approach of CDA (1995a) will be utilized in the present study. It consists of three dimensions or steps (description, interpretation and explanation) which will be followed by the researcher throughout the process of analysis of the CNN's selected news article to manifest its positive "Self" (in-group) and negative "Other" (outgroup). 'Description' is connected with the linguistic part of analysis while 'interpretation' and 'explanation' are connected with the ideological part of the analysis. In fact, this approach connects the two levels of analysis, micro and macro together. Thus, the linguistic structures are described linguistically and, then, interpreted and explained, ideologically. In other words, the first step is concerned with the linguistic analysis while the other two steps are concerned with the ideological one. That is to say, the linguistic analysis serves to achieve the ideological analysis which concerns with overall theme or topic of the news story. As such, the linguistic analysis and ideological analysis will be linked together, 
achieving the main target of the current study. The study's theoretical framework will be illustrated in the following figure (1):

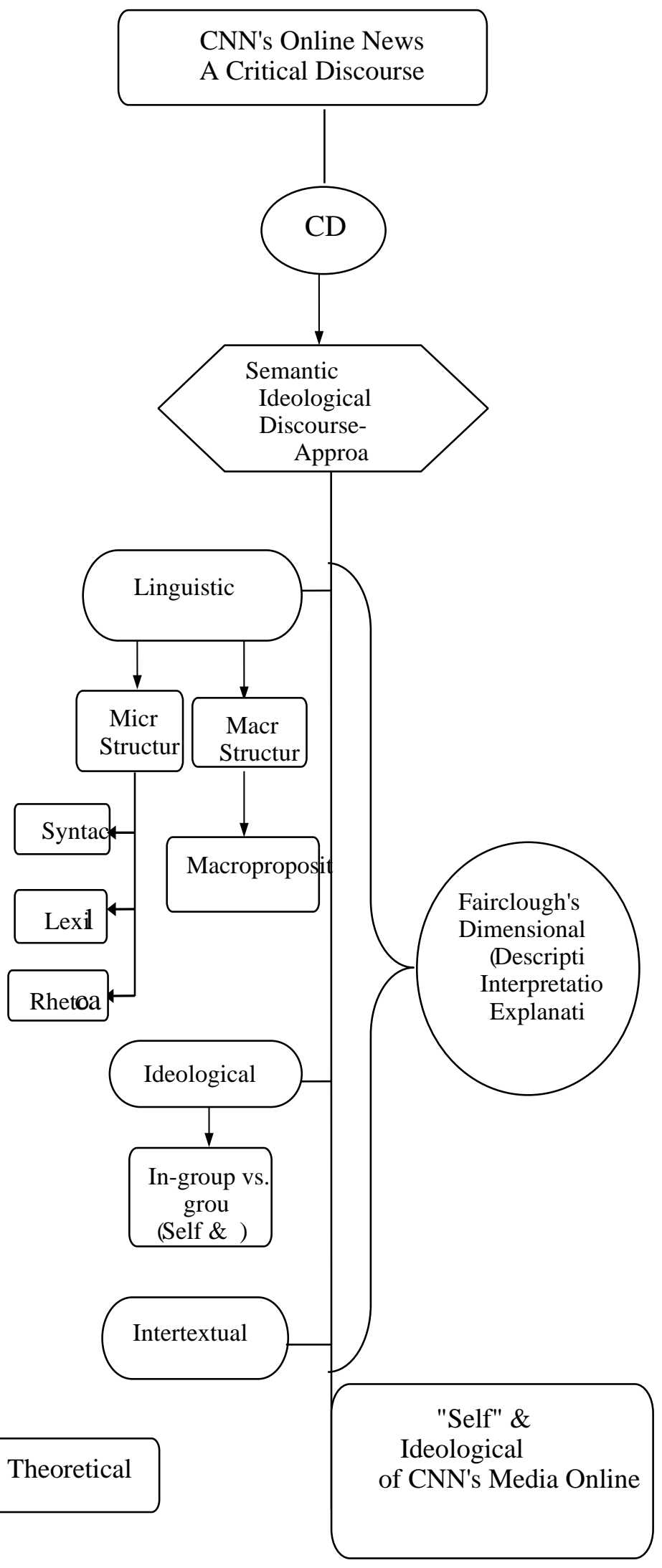

Analysis of CNN's Article-Syria: 83 dead in aerial bombardments on Aleppo, Syria, opposition group says The present case study involves a news story released by CNN's websites on 16 December 2013. It concerns with Syrian internal conflict erupted after the Arab spring upheaval 2011, reflecting the Syrian model. This news story deals with the killing of more than 125 people and injuring scores in Syrian army raids on Aleppo which became a rebel-controlled city. The Syrian people revolted against the Syrian al-Assad regime which rules Syria since 1971 with emergency law imposed on Syria on 1963 (Kilo, 2011). CNN documented a very bloody incident of bombarding Aleppo which reflects critical 
scene of Syria after the Arab spring wave. It is the main reason for selecting this report to be analyzed. The researcher addresses the Syrian model of Arab spring, showing how CNN deals with. It is aimed to reflect its ideological media message to its readers concerning the Syrian conflict that erupted between the Syrian people, on one side, and the SyrianAssad regime, on the other side.

\section{Semantic Macro Structures Analysis}

In the following section, CNN's semantic macro propositions embedded within its news story text will be investigated concentrating on how its ideological view of positive "Self" and negative "Other" is reflected and clarified by the suggested semantic macrostructure.

\section{Thematic Structures}

CNN's news story article spans over 10 sentences, the headline is the first which concentrates on the death of 83 people. It refers, also, to two other pieces of factual information about how and where

the victims died:

a) It is aerial bombardments and

b) It is on Aleppo city. Thus, the headline answers what, where and how the event did happen. Other questions can be answered by reading the whole text, relying on background information about the Syrian internal conflict. The following macro propositions may be listed for the headline:

i) The Syrian opposition received a big blow by the Syrian ruling regime in bombarding Aleppo, its stronghold, severely. ii) 83 People died according to the Syrian opposition sources. iii) As regime-people crisis accelerated, the Syrian internal conflict reached its climax. The above three suggested macro propositions will be reduced into the following main one:

The Syrian regime-people internal conflict reached its climax by Syrian army aerial bombarding Aleppo, the opposition stronghold, killing 83 people.

Thus, the main topic of CNN's news story involves the killing of 83 people in aerial bombardments on Aleppo. But it covers many details that formulate many topics.

The CNN's text yields the following macropropositions:

M1: At least 83 people are dead and 50 others injured in government forces aerial bombardments on 12 rebel neighborhoods in Aleppo where people back President Bashar Al-Assad.

M2: UN estimates 100,000 people died, 2.3 million fled and 4.25 million became refugees in the Syrian conflict erupted in March 2011 after cracking down a peaceful protest which spiraled into bloody full civil war in Syria.

\section{Derivation of Semantic Macrostructure}

The above two macro propositions can be, in turn, reduced into the following main semantic macrostructure that summarizes CNN's whole news story reflecting its themes:

At least 83 people are dead and 50 others injured in Syrian army aerial bombardments on 12 rebel neighborhoods in Aleppo whose people oppose AlAssad regime while UN releases its statistical estimations of victims (100,000 people dead, 2.3 million immigrants and 4.25 million refugees) during the Syrian conflict erupted in March 2011 after cracking down a peaceful protest which spiraled into bloody full civil war in Syria.

\section{CNN's Semantic Macrostructure and van Dijk's Ideological Square}

The suggested semantic macrostructure can be regarded as a comprehensively summarized account of CNN's news text. It is built on the two macro propositions (M1-M2). In one complex sentence, the researcher outlines the whole content of CNN's news story reflecting its "Self" and "Other" ideological view towards the Syrian internal conflict. It answers the following required questions necessary for news writing:

What: killing civilians

Who: 83 people were killed and scores injured?

Where: In Aleppo

When: after Arab spring wave 2010-2011

Why: to punish rebel factions

How: by aerial bombardments conducted by government forces

As such, the researcher summarizes CNN's ideological view of "Self" and "Other" as far as the Syrian internal conflict is concerned as follows:

a) CNN supports the Syrian people sympathizing with their sufferings and pains under Assad-regime rule. Thus, it endorses them drawing them positively. Hence, it legitimizes their struggle and strife to end long years of oppression and dictatorship.

b) CNN antagonizes the Syrian regime rejecting it's bloody and inhumane actions to kill innocent Syrian people. Thus, it antagonizes it drawing it negatively. Hence, it delegitimizes its policies and actions against Syrian people.

In a nutshell, CNN believes in Syrian people presented as the positive "Self", standing behind them to endorse and support. At the same time, CNN does not believe in Assad regime presented as the negative "Other" standing against it to reject and antagonize. Thus, the suggested semantic macrostructure for CNN's news story fulfills its main goal reflecting 
CNN's ideologically oriented view of "Self" and "Other". It is connected with van Dijk's Ideological Square of positive "Self" (ingroup) and negative "Other" (out-group) presentation.

In other words, $\mathrm{CNN}$ expresses:

1) Its support for the Syrian people presented as the positive "Self".

2) Its antagonism for the Syrian regime presented as the negative "Other"

\section{CNN's Semantic Macrostructure and Wodak's Discourse-Historical Approach}

Background information are necessary to understand CNN's ideological view concerning the Syrian conflict. It can be attributed to the American political general view towards the Syrian- Syrian conflict. First, a brief illustration of this view should be presented as on which CNN draws its own view.

The American opinion is manifested in supporting the Syrian people's unprecedented uprising and the opposition rebel factions. American government declared its endorsement to spread democracy, freedom and building democratic institutions in Syria. As such, USA stood with the Syrian people in their revolution rejecting al-Assad regime. But it didn't take any actual step to interfere militarily to topple the regime as what it did in Iraq 2003. In other words, American antagonism to al-Assad regime didn't reach climax to attack Syria, militarily. There are many reasons behind this stance that can be listed as follows (Al-Dakheel, 2012 and Al-Beni, 2012):

1) American loses: the USA is not ready to accept any military and financial losses, especially; Syria is an oil- poor country.

2) American fears: the USA doesn't dare to repeat the failed Iraqi and Afghani experiences avoiding another military and political failure. Furthermore, it is afraid of any unexpected civil bloody chaos similar to that one happened in Iraq and Afghanistan. More specifically, the American government is afraid of the American internal public opinion which has rejected the military interference in both countries. Hence, the Americans are afraid of any risk which may have dire consequences they may face in future.

3) Israeli interest: the Israeli security is the first priority for USA and western countries. For long decades, the Syrian regime didn't commit any action to derail the Israeli security. Thus, indirectly, Israel has a big role in defining the Syria future. Furthermore, Syria is the strategic ally of Israel for more than 40 years (Al-Beni, 2012). They both live together as peaceful neighbors for decades. Thus, al-Assad regime's fall down may harm Israel. For this reason, Americans seek no worries about another Iraqi experience on the borders with Israel (Al-Dakheel, 2012). As Israel rejects al-Assad regime's fall, the American position comes compatible with its first ally in the world (Bakeer. 2012).

4) Iran's role: the USA is afraid of Iran's growing role in the region, especially after its possession of nuclear power and weapon. It is worthy to mention that Iran has close ties with the Assad regime. As such, it threatens that it will not stand idly towards any probable military assault to topple President Bashar al- Assad. Hence, USA looks with suspicion at Iran's role being afraid of its unexpected reaction (CNN, 2013).

5) Islamists' role: the USA is afraid of the Islamists' arrival to power in Syria after Assad's fall down. It is due to their negative role in calling to impose the Islamic law as in Egypt. Thus, the American government is afraid of the Syrian Muslim Brotherhood's probable control of power repeating the Egyptian experience (CNN, 2013).

In general, CNN's news story can be considered as a direct and clear condemnation of the Syrian oppressing and suppressing regime. At the same time, it is a direct support for the Syrian people's struggle for better political and social life. As such, CNN reflects the American political opinion about the Syrian crisis. Hence, it legitimizes the Syrian people's uprising endorsing their struggle against Assad ruling regime. At the same time, it delegitimizes Assad ruling regime rejecting its policies and bloody actions against Syrian people.

\section{Semantic Micro Structures Analysis}

The CNN's syntactic, lexical and rhetorical structures will be under investigation to show how they are exploited for the sake of reflecting its ideological view of positive "Self" and negative

"Other".

\section{Syntactic Structures Analysis}

Two categories will be analyzed and discussed to manifest CNN's ideological view towards Syrian conflict erupted between the Syrian people and their rebel factions, on one side, and the Syrian regime and its supporters, on the other side.

\section{Actor Role}

CNN's news article involves one main group of actors affecting one main group of patients. In other words, the Syrian conflict involves the following two groups:

a) Dominating power: group of actors (the Syrian regime)

b) Dominated power: group of patients (the Syrian people)

They, both, reflect the Syrian civil conflict. This actor-patient relation spans all over the whole text (S.1-S.10). The dominating power (the Syrian regime) launches its aerial bombardments on residential areas for the dominated power (the Syrian people). This act leads to killing and injuring scores of people (S.1, S.2, S.3 and S.4). The main actor- Syrian regime is referred to either implicitly (s.1 and 3) or explicitly (S.2 and S.4). 
It is cemented by opposition organization (LCC)'s accusation against the dominating power- Syrian regime- of dropping barrels of explosives on civilians in Aleppo, the dominated power-Syrian people (S.5 and S.6). Throughout the last sentences, the Syrian regime is the main actor referred to, implicitly, by UN statistics (S.7, S.8 and S.10) and explicitly by background reference (S.9). Thus, within the UN statistics and background information, the Syrian regime is, also, the main actor, explicitly or implicitly, which kills its people cracking down their uprising.

To sum up, the researcher outlines the civil conflict in Syria within the two following powers: i) Actor -dominating power: Syrian regime ii) Patient- dominated power: Syrian people

Within this circle of struggle, CNN draws the first power (actor) negatively due to its role in killing people. At the same time, CNN draws the second power (patient) positively due to its role in standing against the tyrant oppressing regime. By such assertion, CNN expresses its supports for the patient group (the Syrian people) representing the positive "Self" (in-group) and antagonizes the actor group (the Syrian regime) representing the negative "Other" (in-group).

\section{Reporting Past and Present Event}

In its news story, $\mathrm{CNN}$ utilizes a range of past and present tense grammatical structures to convey its media message that reflects its "Self" and "Other" ideological view. The past structures used to cite past information while the present ones used to assert present factual information. The grammatical structures are classified into three categories. They will be analyzed and discussed below.

\section{1) Passive Voice category}

'(Were) conducted' (S.2) is a passive voice structure with both actor and patient are established for the sake of emphasis. 83 Syrians people are the patient who was killed by the Syrian government forces (the actor). CNN, here, accuses the Syrian regime of killing its people, directly. 'Have been injured' (S.8) is a passive voice structure whose patient is established only. It is 'thousands of civilians' (S.8) who are injured during the Syrian conflict according to UN. The agent is omitted but it can be understood from the context of the sentence; the Syrian regime. It is another CNN's condemnation of the Syrian regime's actions against its people. 'Was released' (S.10) is the last passive voice structure to be discussed. The actor-patient relation is direct and clear. The report (patient) was released by Amnesty International, a UN organization, (actor). Within this report, the organization refers to UN statistics of the Syrian dead, injured, immigrants and refugees because of the conflict erupted when the Syrian regime forces cracked down the peaceful demonstration. Thus, the report is an indirect accusation against the regime of committing crimes against Syrian people. As such, CNN, in turn, accuses the Syrian regime of killing and torturing its people.

\section{2) Past and Present Perfect category}

Past and present perfect structures are quietly noticeable in the text. Six structures will be analyzed. It is worthy to note that such structures indicate an action which began in the past and continues till the moment of speaking or of writing the report as far the text, under study, is concerned.

Thus, 'had sustained' (S.3), 'have backed' (S.4), 'has dropped' (S.5), 'have died' (S.7), 'have fled' (S.10) and 'have become (S.10) are all past and present perfect structures that have the same implication that their actions began in the past and continues to the present moment (of writing the news report). Hence, sustaining injuries (S.3), backing rebels (S.4), dropping barrels of explosives (S.5), dying (S.7), fleeing from Syria (S.10) and being refugees (S.10) are all actions whose impacts are still remained to the moment CNN releases its news text. With such structures, CNN intensifies its attack against the Syrian regime accusing it of being the main reason for the deaths and injuries of Syrians. In other words, CNN aims to assert that such crimes are caused by the Syrian regime and its effects are still lingering so far.

\section{3) Past and Present Structures Category}

The simple past tense verbs serve to cite past action. Thus, 'died' (S.2), 'dropped' (S.4), 'cracked down' (S.9) and 'spiraled' (S.9) are all simple past tense verbs confirming actions happened. The simple present tense verbs serve to assert present actions and facts. Thus, 'says' (S.1) and 'estimates' (S.7) are simple present tense verbs that assert factual information. With both tenses, CNN deepens its media message by criticizing the Syrian regime for its actions against its Syrian people. To end this sub- section, CNN utilizes its syntactic categories and structures to assert its support to the Syrian people (positive "Self", in- group) and its antagonism to the Syrian regime (negative "Other", out- group).

\section{Lexical Structures Analysis}

Within this sub-section, the CNN's lexical structures, utilized in its text, will be analyzed. It is aimed to show its ideological view towards the Syrian civil conflict.

\section{CNN's Register of Death and Destruction}

CNN's news story is concerned with the killing and injuring scores of Syrian civilians in aerial bombardments launched by the Syrian army on Aleppo. Hence, CNN concentrates on showing the Syrian regime as an oppressing-destructive power that seeks to destroy the Syrian people, the oppressed-destructed power.

The Syrian regime is denoted by 'government forces' (S.2 and S.9), 'helicopters' (S.4) and 'the government of President Bashar al- Assad' (S.4). Thus, CNN shortens its reference to the Syrian regime with little lexical words. But they are direct in the meaning they used for. 
The Syrian regime orders its 'governmental forces' (S.2) to launch an assault on civilian residents killing and injuring scores of them in 'aerial bombardments' (S.2) on residential areas in Aleppo, the rebel opposition stronghold. It is confirmed by 'Local Coordination Committees' (S.2) which is 'an opposition group' (S.2). The group adds, also, that children and women are among the dead beside what resulted from 'bombardments' (s.3) of 'injuries' (s.3).

Furthermore, 'the helicopters' (S.4), which stand for the regime itself, dropped 'barrel bombs' (S.4) on '12 neighborhoods' (S.4) where people have strongly backed 'rebels' (S.4) opposing the government of President Bashar al-Assad. 'The opposition organization' (S.5), representing the opposition and, in turn, the Syrian people (the oppressed power) said that it is not the first time 'the Syrian regime' (S.5) has dropped 'barrels' (S.5) filled with 'explosives' (S.5) on 'Aleppo neighborhoods' (S.5). The same organization cemented its claims by concluding that 135 people died during 'the conflict' (S.6) on Sunday, totally.

On its part, UN released its report about Syrian conflict referring to statistics of the civilian dead and injured since 'the Syrian conflict' (S.7) began in March 2011. Hence, hundreds of Syrians paid their lives for the Syrian regime's policies and actions. In a reference to background information, CNN states that the Syrian conflict has begun when 'governmental forces' (S.9) cracked down on 'peaceful protesters' (S.9) during the Arab spring wave. It is 'spiraled' (S.9) into 'a bloody full-down civil war' (S.9). The UN Amnesty International, on its part, states that since 'the civil war' (S.10) millions of Syrian people 'have fled' (S.10) and others became 'refugees' (S.10) inside their country, Syria.

To sum up, it is clear that CNN utilizes its lexical terms, within this register, to serve its goal in criticizing the Syrian regime for its aerial bombardments on Aleppo. It is led to the killing and injuring scores of innocent Syrian civilians. By doing this, CNN succeeds in directing public opinion attention towards the Syrian regime's crimes against Syrian people. Hence, CNN presents the Syrian people, positively, as the positive "Self" (in-group) and the Syrian regime, negatively as the negative "Other" (out-group) congruent with van Dijk's Ideological Square theory.

\section{Rhetorical Structures Analysis}

CNN's rhetorical devices will be studied and investigated. It is aimed to show their role in framing CNN's ideological view of "Self" and "Other". Within this sub-section, information sources, numbers and metaphor will be analyzed.

\section{Information Sources}

CNN depends, mainly, on two information sources to achieve its goal of credibility and objectivity, providing the readers with details about the Syrian event. While the first source is internal, the second is external.

The first source: The Internal Information Source

CNN relies on an internal source of information. It is an opposition group (Local Coordination Committees-LCC) whose statement span on the first six sentences of the text (S.1-S.6). Thus, from the beginning of its text, CNN declares its support for the Syrian people and its opposition factions by depending on an opposition group as its main trusted source of information. This means that $\mathrm{CNN}$ believes in opposition issue and struggle against the al-Assad regime. It is real evidence of CNN's support for the opposition by relying on an opposition source of information. Otherwise, the case would be the opposite. This can be regarded as a good prove of CNN's endorsement for Syrian people, believing in their struggle. At the same time, CNN dose not refer to any governmental source and this can be considered as evidence of its bias and inequality between the two sides of the conflict, preferring the first opposition source.

$\mathrm{CNN}$ refers to the opposition group in the first sentence, the headline, acknowledging the death of 83 people in aerial bombardments on Aleppo. It is a basic piece of information that CNN's whole text is concerned with. It depends on an opposition group in providing its readers with the needed details needed to condemn the Syrian regime for the following: 1) The killing and injuring scores of civilians in aerial bombarding residential districts in Aleppo where Syrian people have backed al-Assad regime (S.1, S.2, S.3 and S.4).

2) It is not the first time the regime's forces bombard Aleppo residential neighborhoods leading to kill innocent people (S.6 and S.7).

In fact, the main body of CNN's news story ends with these details about the Syrian event depending on an opposition group. This can be regarded as actual evidence of CNN's trust in the opposition's source rejecting the Syrian regime's one, in turn, CNN's ideological view towards the Syrian conflict will be clarified.

The second source: The External Information Source

CNN relies on an external source of information. It is UN Amnesty International (AI). In its report, the UN organization refers to facts condemning the Syrian regime, indirectly. These facts include reference to statistics about the numbers of the dead, injured, immigrants and refugees; the Syrian victims during the Syrian civil conflict (S.7, S.8 and S.10). Hence, AI concentrates on numeric information clarifying painful facts about the Syrian regime's crimes against Syrian civilians. CNN depends on AI's report in providing the readers with reliable statistical information. Thus, CNN ends its story with information confirmed by UN Amnesty International asserting its credibility. It is a clear evidence for CNN's trust of AI, in particular, and UN, in general. At the same time, it can be considered as another evidence of its support for the Syrian opposition in its struggle against Assad regime.

At the end, the researcher notices that CNN is clear in its support for the Syrian people and antagonism for the Syrian regime. As such, it presents the first as a positive "Self" and the second as a negative "Other". 


\section{Numbers}

CNN's news article is composed of 10 sentences, 9 of them contain numeric references. This asserts that CNN's article is rich with numbers to support facts, first, and to prove objectivity and credibility, secondly. More specifically, CNN prefers to cement its information with numbers serving both goals of objectivity and credibility.

'83' people (S.1) are dead in an aerial bombardment on Aleppo. It is a big number of victims that the Syrian regime is accused of killing them. To emphasize this horrible numeric fact, CNN repeats the same numeric reference of victims preceded by 'at least'. It is at least 83 people died in the bombardments. 'At least' means the dead victims are more than 83. This means that the number of the dead is not fixed and it is increasing with time. 'Serial' (S.2) is an adjective that involves some numeric reference. It means many bombardments, not one. It is a clear accusation of the Syrian regime of attacking civilian districts many times, leading to killing a large number of dead and injured people. Another unfixed number is referred to in S.3 as CNN states that at least '27' children and 'eight' women are among the dead. At the same time, '50' (S.3) people were injured ones. '12' (S.4) neighborhoods in Aleppo are bombarded by dropping barrel bombs on them. This number asserts that: 1) the Syrian regime is cruel and criminal, and 2) rebels' popularity is high as Syrian people in 12 residential districts in Aleppo back the rebel factions.

It is not 'the first' (S.5) time Syrian regime dropped barrels of explosives on the civilian neighborhoods, according to an opposition group. This means that the regime is used to bombard civilians. It is another evidence of its brutality and criminality. '135' (S.6) is the total number of the dead in the conflict Sunday. It is confirmed by the same opposition group. The UN Amnesty International (AI) released its report about the Syrian conflict asserting many numeric facts:

1) More than '100.000' (S.7) people died since the conflict began in March 2011. 'More' means that the number of the dead is not ' 100.000 '. It is a big number of the dead that Syrian regime should carry responsibility for.

2)'Hundreds of thousands' injured people (S.8) is an unfixed number opening the door for high expectations. There are undefined hundreds of thousands of civilians being injured.

3) More than '2.3' (S.10) million people who fled Syria, and another '4.25' (S.10) million Syrians become refugees within their own country. Both numbers reflect painful facts. Syrians, in order to get rid of the Syrian regime's punishment and torture, have one of two bitter choices; either to immigrate outside Syria or to take refugee inside the country.

To be brief, CNN, by referring to AI's statistics, accuses the Syrian regime of destroying Syrian people's life since the civil war has erupted. To cement its accusations, CNN relies on background information asserting that the government forces cracked down on peaceful protesters which spiraled into bloody and full- blown civil war.

To sum up, CNN utilizes numbers, whether they are mentioned by the opposition group or by AI, to condemn the Syrian regime of committing crimes against its Syrian people. By concentrating on using numbers, CNN aims to convince its readers of its ideological view towards the Syrian internal conflict. It supports Syrian people presented as the positive "Self" and antagonizes Syrian regime presented as the negative "Other".

\section{Metaphor}

CNN's news text utilizes one metaphoric image that involves personification. The opposition organization says it is not the first time the Syrian regime has dropped barrels filled with explosives on Aleppo neighborhoods (S.5). This metaphoric image draws the Syrian regime as a strong unmerciful monster dropping barrels filled with explosives on people to kill them. CNN tries to depict the Syrian regime with a negatively framed picture aiming to monopolize the public opinion against it. Thus, this personification is aimed to destroy the overall image of the Syrian regime as an oppressing power whereas the Syrian people are drawn as the oppressed people who need to be endorsed and supported. Thus, it serves CNN's ideological view of supporting the Syrian people and antagonizing the Syrian regime.

To sum up, the researcher's analysis of the micro structures shows CNN's "Self" and "Other" ideological view towards the Syrian internal conflict. It supports the Syrian people taken as a positive "Self" and antagonizes the Syrian regime taken as a negative "Other". As such, CNN's text is connected with van Dijk's ideological Square that concerns with the presentation of positive "Self" (in-group) and negative "Other" (out-group).

\section{Conclusion}

Throughout its text, CNN addresses the Syrian internal conflict erupted between the Syrian oppressing regime and the Syrian oppressed people after the Arab spring revolution. CNN provides its readers with information about the aerial bombardments conducted by the Syrian regime's forces. Such bloody action led to killing and injuring scores of people in Aleppo. CNN is keen to reflect the struggle between the two powers of the Syrian crisis; the oppressing Syrian regime and the oppressed Syrian people. Furthermore, CNN presents its ideological view of "Self" and "Other" towards the Syrian conflict represented by these two powers. To sum up, CNN expresses:

1) Its support for the Syrian people represented as a positive "Self"

2) Its antagonism for the Syrian regime represented as a negative "Other"

As such, CNN's news article reflects van Dijk's theory of Ideological Square of positive "Self" (in-group) and negatives "Other" (out-group) presentation. The CDA study of CNN's news story text titled ' 83 dead in aerial bombardments on Aleppo, Syria, opposition group says' will be outlined in the following table 1. 
Table 1: Summary of CNN's Case Study (4)

\begin{tabular}{|c|c|c|}
\hline Category & Theme & Ideological Representation \\
\hline $\begin{array}{c}\text { 1)Semantic } \\
\text { Macrostructure }\end{array}$ & $\begin{array}{c}\text { To show the Syrian civil war between the } \\
\text { Syrian regime and the Syrian people erupted } \\
\text { in Syria after the Arab spring wave in Arab } \\
\text { homeland } 20102011\end{array}$ & $\begin{array}{l}\text { Positive for the Syrian People } \\
\text { Negative for the } \\
\text { Syrian regime }\end{array}$ \\
\hline \multicolumn{3}{|l|}{$\begin{array}{l}\text { 2)Syntactic } \\
\text { structures }\end{array}$} \\
\hline \multirow[t]{2}{*}{ Actor Role } & $\begin{array}{l}\text { To establish one main actor (Syrian regime) } \\
\text { affecting one main patient (Syrian people) }\end{array}$ & $\begin{array}{l}\text { Positive for the Syrian People } \\
\text { Negative for the Syrian regime }\end{array}$ \\
\hline & To convey information about & Positive for the Syrian People \\
\hline $\begin{array}{l}\text { Reporting Past \& } \\
\text { Present event }\end{array}$ & $\begin{array}{l}\text { past event and to provide background and } \\
\text { historical information }\end{array}$ & $\begin{array}{c}\text { Negative } \\
\text { Syrian regime }\end{array}$ \\
\hline \multicolumn{3}{|l|}{ 3)Lexical structures } \\
\hline $\begin{array}{l}\text { Death and } \\
\text { Destruction } \\
\text { register }\end{array}$ & $\begin{array}{c}\text { To show the Syrian civil war erupted } \\
\text { between the Syrian regime (oppressing } \\
\text { power) and the Syrian people (oppressed } \\
\text { power). }\end{array}$ & $\begin{array}{l}\text { Positive for the Syrian People } \\
\text { Negative for the Syrian } \\
\text { regime }\end{array}$ \\
\hline \multicolumn{3}{|l|}{$\begin{array}{l}\text { 4)Rhetorical } \\
\text { structures }\end{array}$} \\
\hline Information sources & To assert credibility, truth \& objectivity & $\begin{array}{l}\text { Positive for the Syrian People } \\
\text { Negative for the Syrian regime }\end{array}$ \\
\hline Numbers & $\begin{array}{c}\text { To endorse credibility, trust \& objectivity } \\
\text { To assert facts } \& \text { truth }\end{array}$ & $\begin{array}{l}\text { Positive for the Syrian People } \\
\text { Negative for the Syrian regime }\end{array}$ \\
\hline Metaphor & $\begin{array}{c}\text { To reflect the ugly action of the negatively } \\
\text { drawn Syrian regime }\end{array}$ & $\begin{array}{ll}\text { Negative for the } \\
\text { regime }\end{array}$ \\
\hline
\end{tabular}

The following figure 2 outlines CNN's ideological representation of positive "Self" and negative "Other" for its case study that concerns with article titled '83 dead in aerial bombardments on Aleppo, Syria, opposition group says'.

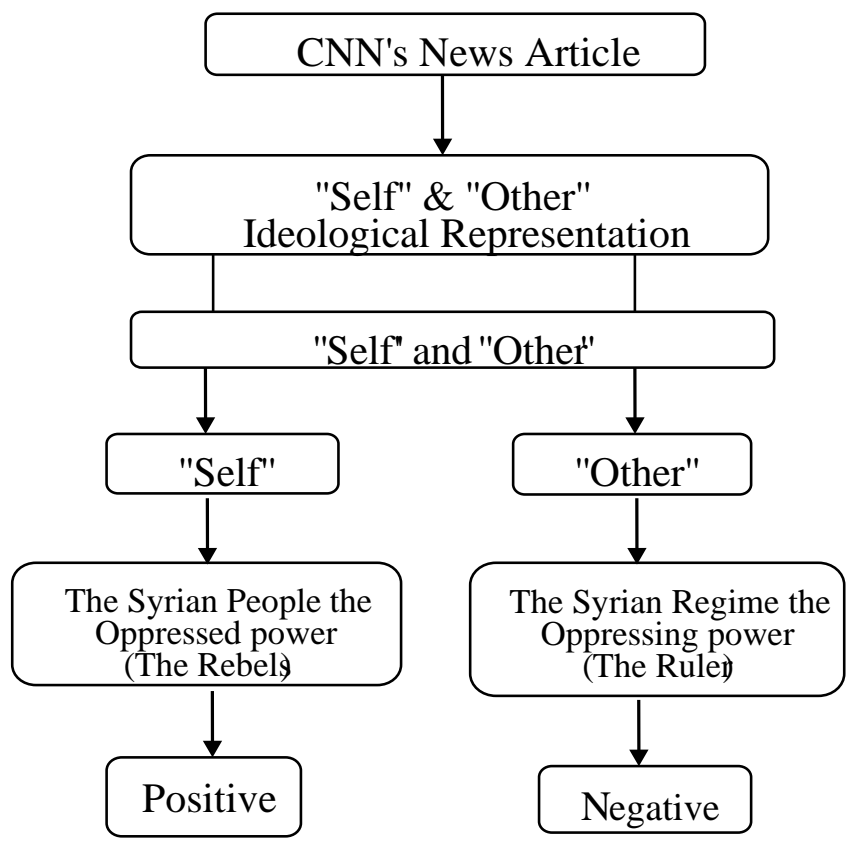

Figure2: CNN's Ideologica

Representation 


\section{References}

[1].Al-Beni, A. (2012). "About the American Attitude towards the Syrian Revolution". In Middle East Newspaper. Issue: 12206

[2].Al-Dakheel, K. (2012). "What is the American Attitude towards the Syrian Revolution". In Alhayat Newspaper published in London 2012

[3].Ali, G. (2011). Hero or terrorist? A comparative analysis of Arabic and Western media depictions of the execution of Saddam. In Discourse \& Communication. London: Sage. 5 (4) 301-335.

[4].Ali, G.A.(2004). English headlines in the Arabic press: a comparative study from an ideological perspective. Unpublished doctoral dissertation, Universiti Sains Malaysia. Malaysia

[5].Bakeer, A. (2012). "The Truth of the American Attitude towards the Syrian Revolution". In Al-Bayan Newspaper, 2012)

[6].Bell, A.(1991). The Language of news media. Oxford: Basil Blackwell, Inc.

[7].Bell, A. and Garret P. (1998). Approaches to media discourse. Oxford: Blackwell Publisher

[8].Ben Ammar, T. (2009). The language of terrorism / Al-Jazeera and the framing of terrorism discourse. Retrieved July 282012 from ProQuest Dissertations and Theses Abstract.

[9].CNN.com (2013). Retrieved August 15 20113from: http://transcripts.cnn.com

[10]. De Chatel, F. (2014). The Role of drought and climate change in the Syrian uprising: Untangling the triggers of the revolution. Middle Eastern Studies, 50 (4), 521-535. Routledge

[11]. el-Nawawy, M. and Powers, S. (2010). Al- Jazeera English: A conciliatory medium in a conflict -driven environment? Global Media and Communication, 6:61. London: Sage

[12]. Fairclough, N. (1995a). Critical discourse analysis: the critical study of language. London \& New York: Longman

[13]. Fairclough, N. (1995b). Media discourse. New York: Arnold.

[14]. Firdous, T. 2009. Al Jazeera English, Presenting a non-Western viewpoint and contesting Western media dominance during the Gaza crisis. Retrieved November 32012 from ProQuest Dissertations and Theses Abstract.

[15]. Fowler , R. (1991; 2013). Language in the news: Discourse and ideology in the press. New York and London: Routledge

[16]. Kilo, M. (2011). Syria ... the road to where? Contemporary Arab Affairs, 4 (4), 431- 444. Routledge Philips, CH. (2012). Syria 's torment. Survival, 54 (4), 67-82. Routledge

[17]. Ross, G. (2008). Introducing War: Visual Analysis of Online Media Discourse on Forces and Weapons of the Iraq Conflict. Carleton University

[18]. Sarihan, A. (2012). Is the Arab spring in the third wave of democratization? The case of Syria and Egypt. Turkish Journal of Politics. 3 (1). Routledge

[19]. van Dijk, T.A. (1980). Macrostructures: An interdisciplinary study of global structures in discourse, interaction, and cognition. New Jersey, U.S.: LEA

[20]. van Dijk, T.A. (1988). News as discourse. Hillside, NJ: Erlbaum van Dijk, T.A. (1998). Ideology: a multidisciplinary approach. London: sage.

[21]. van Dijk, T.A. and Kintsch, W. (1983). Strategies of discourse comprehension. New York: Academic Press.

[22]. Wodak, R. (2001).The discourse -historical approach. In: R. Wodak \& M. Mayer (Eds.), Methods of critical discourse analysis (pp.63-94). London: Sage

[23]. Wodak, R. and Meyer, M. (2009). Methods of critical discourse analysis. London: Sage

[24]. Zisser, E. (2004). Bashar al-Assad and his regime between continuity and change. Orient, 45 (2) , $239-256$.

\section{Appendix: CNN 's News Story Article}

1) CNN: 83 dead in aerial bombardments on Aleppo, Syria, opposition group says

2) At least 83 people died in aerial bombardments conducted by government forces in Aleppo, Syria, Sunday, said the Local Coordination Committees, an opposition group.

3) At least 27 children and eight women were among the dead, the group said; it reported that 50 more people had sustained injuries in the bombardments.

4) Helicopters dropped barrel bombs on 12 neighborhoods in the city, where people have strongly backed rebels opposing the government of President Bashar al-Assad.

5) The opposition organization says it is not the first time the Syrian regime has dropped barrels filled with explosives on Aleppo neighborhoods.

6) The LCC said 135 people died in total in the conflict on Sunday.

7) The United Nations estimates that more than 100,000 people have died since the Syrian conflict began in March 2011.

8) Hundreds of thousands of civilians have also been injured.

9) It began when government forces cracked down on peaceful protesters during the Arab Spring movement, and slowly spiraled into a bloody, full-blown civil war.

10) More than 2.3 million people have fled Syria, and another 4.25 million Syrians have become refugees within their country since the civil war began, according to an Amnesty International report released on Friday. 